\title{
System uncertainties estimation based adaptive robust backstepping control for DC DC buck converter
}

\author{
Ali Hussien Mary ${ }^{1}$, Abbas Hussien Miry ${ }^{2}$, Mohammed Hussein Miry ${ }^{3}$ \\ ${ }^{1}$ Mechatronics Engineering, University of Baghdad, Iraq \\ ${ }^{2}$ Electrical Engineering, Almustansiriyah University, Iraq \\ ${ }^{3}$ Communication Engineering, University of technology, Iraq
}

\begin{tabular}{|c|c|}
\hline Article Info & ABSTRACT \\
\hline Article history: & This paper proposed a novel adaptive robust backstepping control scheme for \\
\hline Received May 20, 2020 & $\begin{array}{l}\text { DC-DC buck converter subjected to external disturbance and system } \\
\text { uncertainty. Uncertainty in the load resistance and the input voltage represent }\end{array}$ \\
\hline Revised Jul 12, 2020 & the big challenge in buck converter control. In this work, an adaptive \\
\hline Accepted Jul 28, 2020 & $\begin{array}{l}\text { estimator for matched and mismatched uncertainties based backstepping } \\
\text { control is applied for DC-DC buck converter. The updating laws are }\end{array}$ \\
\hline Keywords: & $\begin{array}{l}\text { determined based on the lyapunov theorem. Thus, the difference between } \\
\text { the estimated parameters and actual parameters converges to zero. }\end{array}$ \\
\hline $\begin{array}{l}\text { Backstepping } \\
\text { Buck converter }\end{array}$ & $\begin{array}{l}\text { The proposed control method is compared with the conventional sliding } \\
\text { mode control and integral sliding mode control. Simulation results } \\
\text { demonstrate the effectiveness and robustness of the proposed controller. }\end{array}$ \\
\hline
\end{tabular}

Control

Robust control

Uncertainties

This is an open access article under the CC BY-SA license.

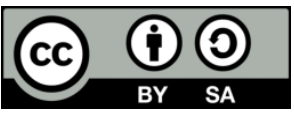

\section{Corresponding Author:}

Ali Hussien Mary,

Department of Mechatronics Engineering,

University of Baghdad, Iraq.

Email: alimary76@kecbu.uobaghdad.edu.iq

\section{INTRODUCTION}

Recently, a DC-DC converter is applied successfully in many modern applications such as wind turbine systems, a driver for a DC motor, communication systems, automation systems, and photovoltaic systems [1-5]. The buck, boost, and buck/boost are important topologies of the DC-DC converter, and all these topologies try to regulate the output voltages and track the desired voltage in the presence of the system uncertainty and external disturbance [6-8]. The DC-DC buck converter consists of an inductor, capacitor, load resistance, and switching transistor. The switching circuit is the important element in the DC-DC buck converter, and it's the main reason for the nonlinearity behavior of the DC-DC converter. This nonlinearity and uncertainty of the DC-DC converter model make the control of the DC-DC converter as a big challenge. Hence, many control schemes had been presented to control the DC-DC converter [9-13]. Soft computing algorthims had been applied sucesfuly in tuninig controller ganis for many complicated systems [14-18]. sliding mode control (SMC) is an efficient and popular control approach that has been applied effectively for control many nonlinear systems such as robotic systems, DC-DC converter, etc. Fast response and strong robustness are the important advantages of SMC [19-22]. On the other hand, the chattering and steady-state errors are a major drawback of the SMC. Moreover, SMC is robust only to the matched uncertainty and disturbance. As a result, standard SMC is not qualified for DC-DC converter. Recent publications indicate great attention of researchers about these drawbacks by suggesting different strategies like disturbance observer with SMC [23], uncertainty and disturbance observer with SMC [24]. Backstepping control is another efficient control scheme that has been widely considered due to its simplicity in design and 
implementation. However, its control law required the exact dynamic model of the control system, which is not possible in practice applications. The motivation of this work is to improve the Backstepping control and overcome this shortage by applying adaptive techniques to estimated unknown parameters (matched and mismatched uncertainties) in the presence of the load resistance and input voltage variations. This paper aims to design an adaptive robust control scheme for DC-DC converter with a good and robust performance regardless of the variations of the load resistance, the input voltage, and external disturbance. A novel control law has been presented to ensure the robustness of DC-DC converter against matched and unmatched uncertainties.

\section{DC-DC BUCK MODEL DEFINITION}

This section describes the dynamic model of the DC-DC buck converter, which is shown in Figure 1. This converter is composed of DC voltage source, transistor switch, Diode, indictor, capacitor, and load resistance. There are two models for this converter based on the position of the switch (ON and OFF). When the transistor switch at $\mathrm{ON}$ position the state-space model is:

$$
\left.\begin{array}{l}
E=L i_{L}+v_{o} \\
C \dot{v}_{o}=i_{L}-\frac{v_{o}}{R}
\end{array}\right\}
$$

At OFF position, the state space model is

$$
\left.\begin{array}{c}
0=L i_{L}+v_{o} \\
C \dot{v}_{o}=i_{L}-\frac{v_{o}}{R}
\end{array}\right\}
$$

where $E$ is the DC input voltage, $R$ is the load resistance, $L$ is the inductance, $i_{L}$ is the indicator current, $C$ is the capacitance, and $v_{o}$ is the output voltage. The average state-space model of the converter can be expressed as follows [18]:

$$
\begin{aligned}
& \frac{d v_{O}}{d t}=\frac{1}{C} i_{L}-\frac{1}{R C} v_{O} \\
& \frac{d i_{L}}{d t}=-\frac{1}{L} v_{O}+\frac{1}{L} \mu E
\end{aligned}
$$

$\mu \in[0,1]$ denotes the control signal that regulates the duty ratio of PWM in such way that makes output voltage tracks the source voltage. The average model of the buck converter assumes ideal components. However, in practice, the load resistance and input voltage are unknown exactly and they represent the significant uncertainties of this converter. Therefore, the state-space model will be rewritten in terms of nominal load resistance $R_{o}$, and nominal input voltage $E_{o}$.

$$
\begin{aligned}
& \frac{d v_{O}}{d t}=\frac{1}{C} i_{L}-\frac{v_{O}}{C}\left[\frac{1}{R}\right]=\frac{1}{C} i_{L}-\frac{v_{O}}{C R_{O}}+\frac{v_{O}}{C}\left[\frac{1}{R_{O}}-\frac{1}{R}\right] \\
& \frac{d i_{L}}{d t}=-\frac{1}{L} v_{o}+\frac{1}{L} \mu E_{o}+\frac{1}{L} \mu\left(E-E_{o}\right)
\end{aligned}
$$

Then the buck model in (6) and (8) can be represent as

$$
\begin{aligned}
& \dot{x}_{1}=\frac{1}{C} x_{2}-\frac{x_{1}}{C R_{o}}+d_{1} \\
& \dot{x}_{2}=-\frac{1}{L} x_{1}+\frac{1}{L} \mu E_{o}+d_{2}
\end{aligned}
$$

where $x_{1}=v_{o}, x_{2}=i_{L}, d_{1}=\frac{v_{o}}{C}\left[\frac{1}{R_{o}}-\frac{1}{R}\right]$, and $d_{2}=\frac{1}{L} \mu\left(E-E_{o}\right)$. Let

$$
\begin{aligned}
& \theta=\frac{1}{R_{o}}-\frac{1}{R} \\
& \delta=E-E_{o}
\end{aligned}
$$


Then $d_{1}$ and $d_{2}$ become

$$
\begin{aligned}
& d_{1}=\frac{x_{1}}{C} \theta \\
& d_{2}=\frac{1}{L} \mu \delta
\end{aligned}
$$

It can be noticed that $\theta$ and $\delta$ are unknown due to the uncertainty of the load resistance and the input source. In literature, since the uncertainty $d_{1}$ appears in the divertive of the load voltage expression (11), which is not dependent directly on the input; thus $d_{1}$ is called mismatched uncertainty, and $d_{2}$ that expressed in (12) is called a matched uncertainty. The objective of this work is to design a robust controller that makes the output voltage tracks the reference voltage in the presence of mismatched and matched uncertainties.

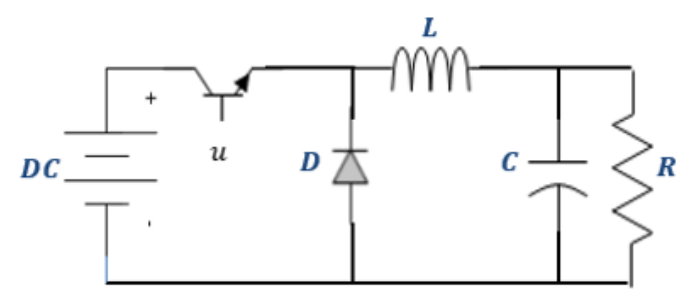

Figure 1. DC-DC buck converter

\section{POPOSED CONTROL SCHEME}

To compensate effects of external disturbance, matched and mismatched uncertainties that caused mainly due to the changes in the load resistance and input voltage, this paper presented an adaptive estimation for the mismatched uncertainty and matched uncertainty in such a way that ensures the convergence of these uncertainties based on adaptive backstepping control. At first, mismatched uncertainty $d_{1}$ and matched uncertainty $d_{2}$ are estimated, then, these estimated values are used in design the robust adaptive backstepping controller. The block diagram of the proposed controller is shown in Figure 2.

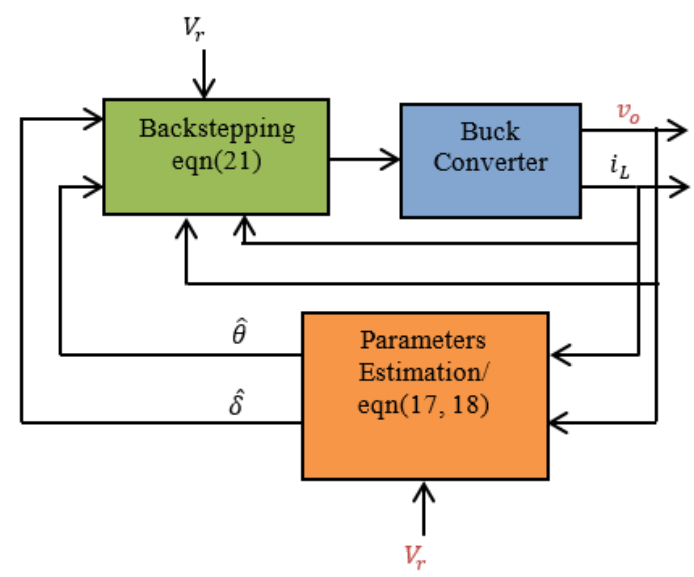

Figure 2. Block diagram of the proposed control scheme

\subsection{Adaptive Estimation of unknown parameters law}

This section explains the steps related to estimating the unknown buck model parameters required in design the control signal for the DC-DC buck converter. The proposed control scheme assumes the following:

- All states are measurable

- This work assumes constant or slow variations of the load resistance 
Step 1: Define the tracking errore $e_{1}$ and its derivative,

$$
\begin{aligned}
& e_{1}=x_{1}-x_{1 d} \\
& \dot{e}_{1}=\dot{x}_{1}-\dot{x}_{1 d}
\end{aligned}
$$

where $x_{1 d}=V_{r}$ denotes the desired reference voltage. Let $\hat{\theta}$ represent the estimation of the mismatched uncertainty $\theta$ and it is updated as follows:

$$
\dot{\hat{\theta}}=\rho_{1} e_{1} \frac{x_{1}}{C}
$$

where $\rho_{1}$ is adaption rate. Also, matched uncertainty represntes by $\hat{\delta}$ can be estimated and updated with the adaption rate $\rho_{2}$ according to the following suggested formula.

$$
\dot{\hat{\delta}}=\rho_{2} \frac{1}{L} \mu e_{2}
$$

\subsection{Robust backstepping control design}

Now, to design the proposed controller

Step 2: Define a virtual control input $x_{2 d}$ as

$$
x_{2 d}=v_{o}\left(\frac{1}{R_{0}}-\hat{\theta}\right)+c \dot{x}_{1 d}-c k_{1} e_{1}
$$

Step 3: Let $e_{2}$ denotes the difference between the virtual control input and the indicator current

$$
e_{2}=x_{2}-x_{2 d}
$$

Step 4: Finally, the proposed control law can be expressed as

$$
\mu=\frac{L}{\delta+E_{o}}\left[-k_{2} e_{2}-\left(\frac{1}{C}-\frac{1}{L}\right) e_{1}+\frac{1}{L} x_{1 d}+\dot{x}_{2 d}\right]
$$

\subsection{Stability analysis}

Theorem 1: Consider the DC-DC buck converter system described in (1) with unknown mismatched and matched uncertainties. If the robust backstepping control scheme designed with adaptation laws of mismatched and matched uncertainties are derived as in (15) and (16) and the robust controller which derived as in (19), then the closed-loop system is asymptotically stable.

Proof. : Define $V_{1}$ as quadratic Lyapunov function as

$$
\mathrm{V}_{1}=\frac{1}{2} \mathrm{e}_{1}{ }^{2}+\frac{1}{2} \rho_{1}{ }^{-1} \tilde{\theta}^{2}
$$

where $\tilde{\theta}$ is estimation error of mismatched uncertainty and give as

$$
\begin{aligned}
& \tilde{\theta}=\theta-\hat{\theta} \\
& \dot{\mathrm{V}}_{1}=\mathrm{e}_{1} \mathrm{e}_{1}+\rho_{1}{ }^{-1} \tilde{\theta} \dot{\tilde{\theta}} \\
& =\mathrm{e}_{1}\left(\dot{\mathrm{x}}_{1}-\dot{\mathrm{x}}_{1 \mathrm{~d}}\right)+\rho^{-1} \tilde{\theta} \dot{\tilde{\theta}} \\
& \dot{\tilde{\theta}}=\dot{\theta}-\dot{\hat{\theta}} \\
& \dot{\mathrm{V}}_{1}=\mathrm{e}_{1}\left(\frac{1}{\mathrm{C}} \mathrm{x}_{2}-\frac{\mathrm{x}_{1}}{\mathrm{CR}}+\mathrm{d}_{1}-\dot{\mathrm{x}}_{1 \mathrm{~d}}\right)+\rho_{1}{ }^{-1} \tilde{\theta}(\dot{\theta}-\dot{\hat{\theta}}) \\
& =\mathrm{e}_{1}\left(\frac{1}{\mathrm{c}}\left(\mathrm{e}_{2}+\mathrm{x}_{2 \mathrm{~d}}\right)-\frac{\mathrm{x}_{1}}{\mathrm{CR}_{\mathrm{o}}}+\mathrm{d}_{1}-\dot{\mathrm{x}}_{1 \mathrm{~d}}\right)+\rho_{1}{ }^{-1} \tilde{\theta}(\dot{\theta}-\dot{\hat{\theta}}) \\
& =\frac{1}{\mathrm{C}} \mathrm{e}_{1} \mathrm{e}_{2}+\mathrm{e}_{1}\left(\frac{\mathrm{x}_{2 \mathrm{~d}}}{\mathrm{C}}-\frac{\mathrm{x}_{1}}{\mathrm{CR}_{\mathrm{o}}}+\frac{\mathrm{x}_{1}}{\mathrm{C}}(\tilde{\theta}+\hat{\theta})-\dot{\mathrm{x}}_{1 \mathrm{~d}}\right)+\rho_{1}{ }^{-1} \tilde{\theta}(\dot{\theta}-\dot{\hat{\theta}})
\end{aligned}
$$




$$
\begin{aligned}
& =\frac{1}{\mathrm{C}} \mathrm{e}_{1} \mathrm{e}_{2}+\mathrm{e}_{1}\left(\frac{\mathrm{x}_{2 \mathrm{~d}}}{\mathrm{C}}-\frac{\mathrm{x}_{1}}{\mathrm{C} \mathrm{R}_{\mathrm{o}}}+\frac{\mathrm{x}_{1}}{\mathrm{C}} \hat{\theta}-\dot{\mathrm{x}}_{1 \mathrm{~d}}\right)+\left(\mathrm{e}_{1} \frac{\mathrm{x}_{1}}{\mathrm{C}}-\rho^{-1} \dot{\hat{\theta}}\right) \tilde{\theta}+\rho_{1}{ }^{-1} \tilde{\theta} \dot{\theta} \\
& =\frac{1}{\mathrm{C}} \mathrm{e}_{1} \mathrm{e}_{2}-\mathrm{k}_{1} \mathrm{e}_{1}{ }^{2}+\rho_{1}{ }^{-1} \tilde{\theta} \dot{\theta}
\end{aligned}
$$

Remark 1. As described in Assumption 2, if the load uncertainty is slowly time-varying or load resistance is a constant value, then $\dot{\theta}$ is zero, or it can be neglected. Therefore, (28) becomes

$$
\dot{\mathrm{V}}_{1}=\frac{1}{\mathrm{C}} \mathrm{e}_{1} \mathrm{e}_{2}-\mathrm{k}_{1} \mathrm{e}_{1}{ }^{2}
$$

Remark 2. If the load resistance is varying fast with the time, then, (29) can be written as

$$
\begin{aligned}
& \dot{\mathrm{V}}_{1}=\frac{1}{\mathrm{C}} \mathrm{e}_{1} \mathrm{e}_{2}-\mathrm{k}_{1} \mathrm{e}_{1}{ }^{2}+\epsilon \\
& \epsilon=\rho_{1}{ }^{-1} \tilde{\theta} \dot{\theta}
\end{aligned}
$$

In this case, appropriate choice for the adaption rate and positive gain $\left(\rho_{1}\right.$ and $\left.\mathrm{k}\right)$ can ensures a minimum tracking error. By integrating(6) w.r.t. time, explicit expression of the estimated mismatched uncertainty can be written as

$$
\widehat{\theta}=\int_{0}^{t} e_{1} \rho_{1} \frac{x_{1}}{C} d \tau
$$

Remark 3. This updating law shows that there is no need to determine the derivative of any measured signal which is very important in a particular application because the differential produces a noisy signal.

A second Lyapunov function is a candidate to design control law of the proposed controller as well as updating law of the matched uncertainty. The function is

$$
\mathrm{V}_{2}=\mathrm{V}_{1}+\frac{1}{2} \mathrm{e}_{2}{ }^{2}+\frac{1}{2} \rho_{2}{ }^{-1} \tilde{\delta}^{2}
$$

where $\tilde{\delta}=\delta-\widehat{\delta} \cdot \tilde{\delta}$ denotes the estimation error of the matched uncertainty.

$$
\begin{aligned}
\dot{\mathrm{V}}_{2}= & \dot{\mathrm{V}}_{1}+\mathrm{e}_{2} \dot{\mathrm{e}}_{2}+\rho_{2}{ }^{-1} \tilde{\delta} \dot{\tilde{\delta}} \\
\dot{\mathrm{V}}_{2}= & \dot{\mathrm{V}}_{1}+\mathrm{e}_{2} \dot{\mathrm{e}}_{2}+\rho_{2}{ }^{-1} \tilde{\delta} \dot{\tilde{\delta}} \\
\dot{\mathrm{V}}_{2}= & \frac{1}{\mathrm{C}} \mathrm{e}_{1} \mathrm{e}_{2}-\mathrm{k}_{1} \mathrm{e}_{1}{ }^{2}+\mathrm{e}_{2}\left(\dot{\mathrm{x}}_{2}-\dot{\mathrm{x}}_{2 \mathrm{~d}}\right)+\rho_{2}{ }^{-1} \tilde{\delta}(\dot{\delta}-\dot{\hat{\delta}}) \\
\dot{\mathrm{V}}_{2}= & \frac{1}{\mathrm{C}} \mathrm{e}_{1} \mathrm{e}_{2}-\mathrm{k}_{1} \mathrm{e}_{1}{ }^{2}+\mathrm{e}_{2}\left(-\frac{1}{\mathrm{~L}} \mathrm{x}_{1}+\frac{1}{\mathrm{~L}} \mu \mathrm{E}_{\mathrm{o}}+\mathrm{d}_{2}-\dot{\mathrm{x}}_{2 \mathrm{~d}}\right)+\rho_{2}{ }^{-1} \tilde{\delta}(\dot{\delta}-\dot{\hat{\delta}}) \\
\dot{\mathrm{V}}_{2}= & -\mathrm{k}_{1} \mathrm{e}_{1}{ }^{2}+\mathrm{e}_{2}\left(\left(\frac{1}{\mathrm{C}}-\frac{1}{\mathrm{~L}}\right) \mathrm{e}_{1}-\frac{1}{\mathrm{~L}} \mathrm{x}_{1 \mathrm{~d}}+\frac{1}{\mathrm{~L}}\left(\mathrm{E}_{\mathrm{o}}+\widehat{\delta}\right) \mu-\dot{\mathrm{x}}_{2 \mathrm{~d}}\right) \\
& +\left(\frac{1}{\mathrm{~L}} \mu \mathrm{e}_{2}-\rho_{2}{ }^{-1} \hat{\tilde{\delta}}\right) \tilde{\delta}+\rho_{2}{ }^{-1} \tilde{\delta} \dot{\delta} \\
\dot{\mathrm{V}}_{2}= & -\mathrm{k}_{1} \mathrm{e}_{1}{ }^{2}-\mathrm{k}_{2} \mathrm{e}_{2}{ }^{2}+\rho_{2}{ }^{-1} \tilde{\delta} \dot{\delta}
\end{aligned}
$$

Remark 4. If the input source is slowly time-varying or it's constant, then $\dot{\delta}$ is zero, or it can be neglected. Therefore, (30) becomes

$$
\dot{\mathrm{V}}_{1}=-\mathrm{k}_{1} \mathrm{e}_{1}{ }^{2}-\mathrm{k}_{2} \mathrm{e}_{2}{ }^{2}
$$

Remark 5. If the input source is varying fast with the time, then, (40) can be written as

$$
\begin{aligned}
& \dot{\mathrm{V}}_{1}=-\mathrm{k}_{1} \mathrm{e}_{1}{ }^{2}-\mathrm{k}_{2} \mathrm{e}_{2}{ }^{2}+\epsilon_{2} \\
& \epsilon_{2}=\rho_{2}{ }^{-1} \tilde{\delta} \dot{\delta}
\end{aligned}
$$


In this case, an appropriate choice for the adaption rate and positive gain $\left(\rho_{2} \mathrm{k}_{1}\right.$ and $\left.\mathrm{k}_{2}\right)$ can ensure the minimum tracking error. Thus

$$
\dot{\mathrm{V}}_{2}=-\mathrm{k}_{1} \mathrm{e}_{1}{ }^{2}-\mathrm{k}_{2} \mathrm{e}_{2}{ }^{2}+0 \leq 0
$$

Since $\dot{V}_{2} \leq 0$, which means $V_{2}(t) \leq V_{2}(0)$, this indicate that the $\mathrm{e}_{1}(\mathrm{t})$ and $\mathrm{e}_{2}(\mathrm{t})$ are bounded.

$$
\begin{aligned}
& \text { Define } \psi=-\dot{V}_{2} \\
& \int_{0}^{t} \psi(\tau) d \tau=V_{2}(0)-V_{2}(t)
\end{aligned}
$$

Since $V_{2}(0)$ is bounded and $V_{2}(t)$ is less than $V_{2}(0)$, then, it easily obtained the following result

$$
\lim _{t \rightarrow \infty} \int_{0}^{t} \psi(\tau) d \tau<\infty
$$

According to the Barbalat's Lemma, it can be get $\lim _{t \rightarrow \infty} \psi(\tau)=0$. This indicate that the $e_{1}(t)$ and $\mathrm{e}_{2}(\mathrm{t})$ converge to zero as $\mathrm{t} \rightarrow \infty$. According to this prove, the mention theorem can be concluded.

\section{SIMULATION RESULTS}

To illustrate the effectiveness and robustness of the proposed control method, a simulation model of the DC-DC buck converter is built by using MATLAB. The nominal model parameters of the converter selected as follows: $E=20 \mathrm{~V}, V_{r}=10 \mathrm{~V}, R=100 \Omega, C=1000 \mu \mathrm{F}$, and $L=4.7 \mathrm{mH}$. Conventional SMC (CSMC) and Integral SMC (ISMC) are taken for comparison. The control law of CSMC is:

$$
\begin{aligned}
& u^{S M C}=\frac{L}{E}\left[\frac{\alpha_{1}}{C R_{0}}+\frac{1}{C}\right] x_{1}-\frac{\alpha_{1}}{C} x_{2}-\alpha_{2} \operatorname{sgn}(s) \\
& s=e_{2}+\alpha e_{1}
\end{aligned}
$$

For the ISMC design, this section applies the procedures of ISMC design in [25] for control DC-DC buck converter. The sliding surface is adopted to tackle the effects of matched and mismatched uncertainties. The following sliding surface is used,

$$
s=e_{2}+\beta_{1} e_{1}+\beta_{2} \int e_{1} d t
$$

Then ISMC control law will be as

$$
u^{I S M C}=\frac{L}{E}\left[\frac{\beta_{1}}{C R_{0}}-\beta_{2}+\frac{1}{C}\right] x_{1}-\frac{L}{E} \frac{\beta_{1}}{C} x_{2}-\beta \operatorname{sgn}(s)
$$

For best comparison between these controllers, their parameters have been selected to achieve their optimal performances. Then, the parameters of these controllers are chosen as follows: $\alpha_{1}=\beta_{1}=30$, $\beta_{2}=275$, and $\alpha_{2}=\beta=450$, while the proposed controller's parameter selected as: $k_{1}=75, k_{2}=50$, $\rho_{1}=100$, and $\rho_{2}=100$. The objective of this work is to keeps a stable load voltage in spite of the presence of mismatched and matched uncertainties. Integral absolute error (IAE), Integral time absolute error (ITAE), and percentage overshoot (PO) have been used for the performance comparison.

$$
\begin{aligned}
& I A E=\int_{0}^{t f}|e(t)| d t \\
& I T A E=\int_{0}^{t f} t|e(t)| d t
\end{aligned}
$$

The performance of the three controllers are tested in three different simulation scenarios.

- Case 1: Step change of the load resistance

The robustness of the proposed controller is tested by changing the load resistance from 100 to 60 at $5 \mathrm{sec}$ and then switch to 85 at $15 \mathrm{sec}$. The results are shown in Figure 3. It is seen that the proposed controller and ISMC provide a good and robust response with zero steady tracking error against the step variation of 
the load resistance. However, the conventional SMC is unable to achieve the desired voltage due to the unmatched uncertainty. In addition, the proposed control scheme response with a very small overshoot with respect to the ISMC, which responds with a very high overshoot. Moreover, the control signal of the proposed controller is smothering than other control signals. Table 1 lists the IAE, ITAE, and PO values for all controllers. This table indicates the effectiveness of all methods but with slightly better performance for the proposed control scheme.
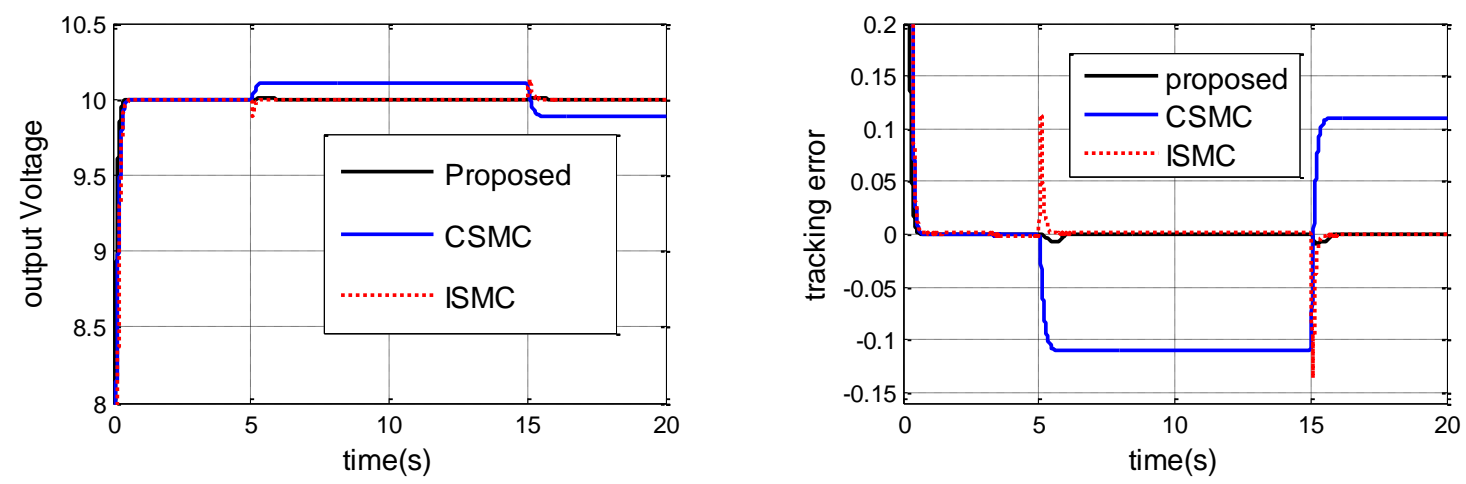

Figure 3. Response of the buck converter when subjected to step varying load

Table 1. Comparison performances of case 1

\begin{tabular}{cccc}
\hline & IAE & ITAE & PO \\
\hline Proposed & 0.4337 & 0.1327 & 0.0009 \\
ISMC & 0.7668 & 0.3238 & 0.0110 \\
CSMC & 2.1969 & 0.6023 & 0.0136 \\
\hline
\end{tabular}

- Case 2: Continuous varying of the load resistance

To approve the successes and robustness of the proposed control scheme in the presence of a continuous time-varying of unmatched uncertainty, at $\mathrm{t}=5 \mathrm{sec}$, the load resistance is changed from the nominal value $(100)$ to $R=100+50 \sin (\pi t)$. The performances of the controllers are shown in Figure 4. As seen, CSMC is unable to track the desired voltage with high oscillation about the desired output voltage. The performance of the ISMC is better than CSMC but with nonzero steady tracking error. However, the proposed control scheme provides good and robust performance with zero steady tracking error and fast response to the change of the load resistance. Moreover, the control signal of the proposed controller is unchanged despite the presence of the load uncertainty. Table 2 lists the IAE, ITAE, and PO values for all controllers. These values reveal the superiority of the proposed control method in terms of transient specifications and steady-state.
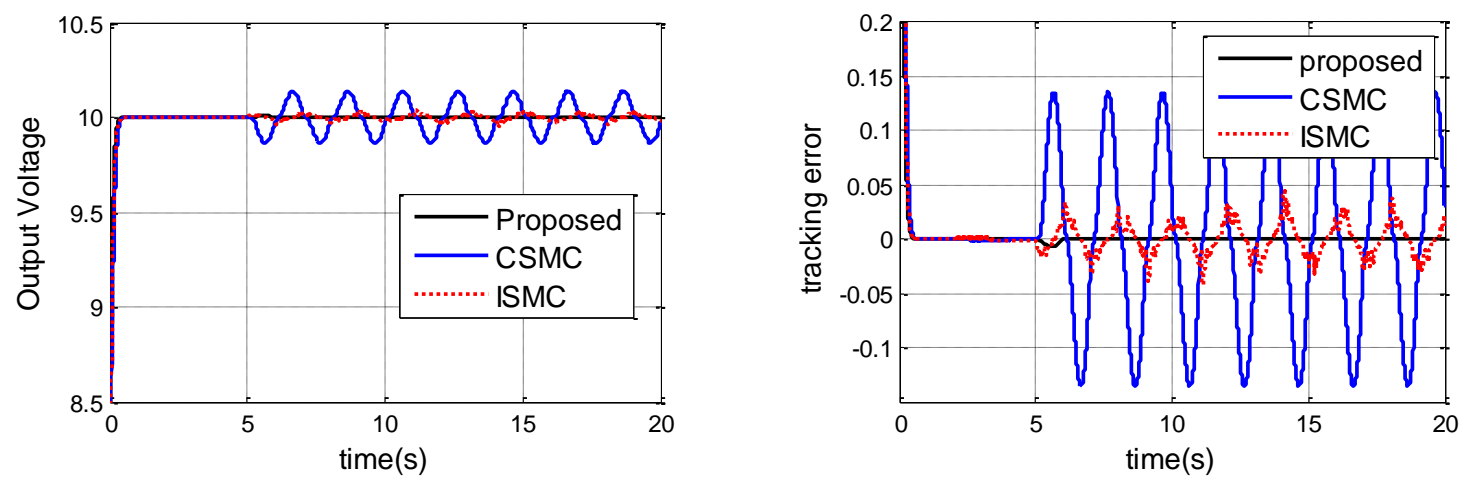

Figure 4. Response of the buck converter when subjected to continuous varying load 
Table 2. Comparison performances of case 2

\begin{tabular}{lccc}
\hline & IAE & ITAE & PO \\
\hline Proposed & 0.1886 & 0.0366 & 0.0007 \\
ISMC & 0.4015 & 2.3290 & 0.0136 \\
CSMC & 1.3576 & 14.0462 & 0.0042 \\
\hline
\end{tabular}

- Case 3: Step change of the input voltage

Robustness to the matched uncertainty is checked by changing DC voltage from $24 \mathrm{~V}$ to 20 Vat $\mathrm{t}=4$ $\mathrm{sec}$ and then drop to $18 \mathrm{~V}$ at $\mathrm{t}=10 \mathrm{sec}$. the simulation response to the matched uncertainty which represented by the step change of the input voltage is shown in Figure 5 and peromance indexes listed in Table 3. As expected, due to the inherent stability of SMC and ISMC, the performances of these controllers achieve good performances and strong robustness against the matched uncertainties when the matched uncertainty remains under the upper bound of uncertainty.

Figure 5 shows the undesired transients response of the ISMC at $t=4 \mathrm{sec}$ due to the high overshoot to the transient response of the proposed controller. The problem appears if the magnitude of the matched uncertainty is greater than the switching gain. In this case, the output voltage of CSMC will be unable to track the desired voltage, as shown in Figure 5 when the input voltage changes to 20 at $\mathrm{t}=14 \mathrm{sec}$. In other words, the proposed control scheme provides good performances and keeps a stable output voltage with a very short time transient at $\mathrm{t}=4 \mathrm{sec}$ and $\mathrm{t}=10 \mathrm{sec}$ in which the input voltage had been changed. Moreover, the control signal of the proposed control is very smooth concerning the CSMC and SMC, which suffer from high chattering. Table 3, which lists the IAE, ITAE, and PO values, ensures better performance and high robustness of the proposed method to the variations of the input voltage.
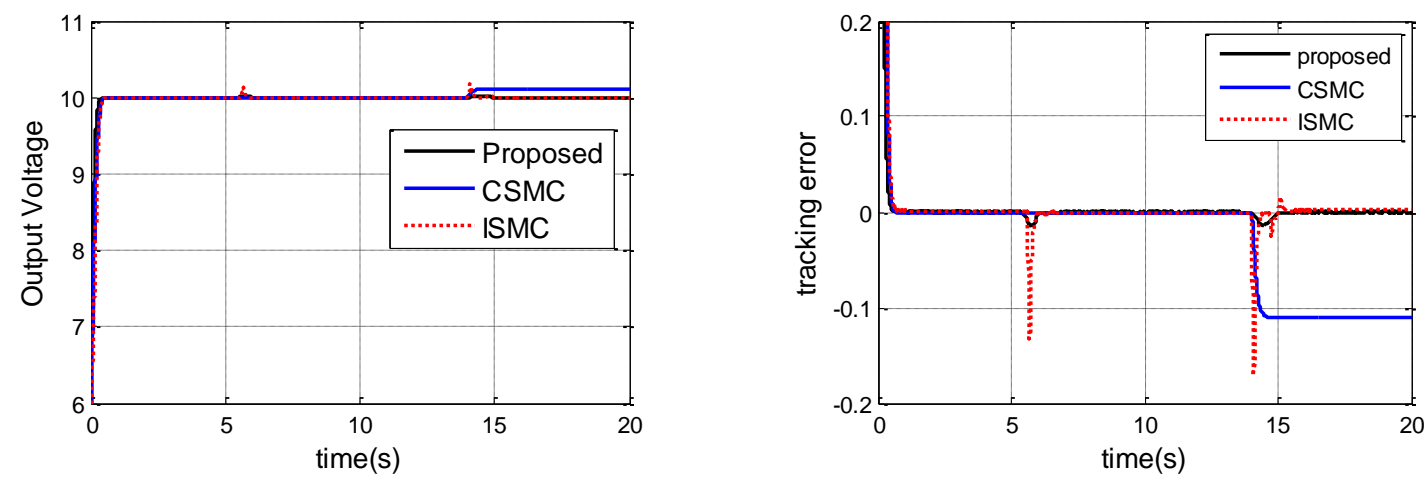

Figure 5. Response of the buck converter when subjected to step change of the input voltage

Table 3. Comparison performances of case 3

\begin{tabular}{lccc}
\hline & IAE & ITAE & PO \\
\hline Proposed & 0.4387 & 0.1881 & 0.0014 \\
ISMC & 0.7737 & 0.8161 & 0.0110 \\
CSMC & 1.2357 & 11,1213 & 0.0171 \\
\hline
\end{tabular}

\section{CONCLUSIONS}

This paper presents an adaptive robust backstepping control for the buck converter feeding unknown load with the unknown input voltage. The proposed controller is designed based on the estimation of the matched and mismatched uncertainties. The updating laws for the load resistance and input voltage are derived based Lyapunov theorem, which ensures the stability of the closed-loop controlled system. Simulations results are presented to demonstrate the high efficiency of the proposed controller.

\section{REFERENCES}

[1] N.I.P. de León Puig, et al., "An Adaptive Predictive control scheme with dynamic Hysteresis Modulation applied to a DC-DC buck converter," ISA Transactions, 2020.

[2] S. K. Pandey, et al, "Robust control of mismatched buck DC-DC converters by PWM-based sliding mode control schemes," Control Engineering Practice, vol. 1, no. 84, pp. 183-93, 2019. 
[3] P. Dai, S. Cauet, and P. Coirault, "Disturbance rejection of battery/ultracapacitor hybrid energy sources," Control Engineering Practice, vol. 54, pp. 166-175, 2016.

[4] W. Qi, S. Li, S. Tan, S. R. Hui, "Parabolic-modulated sliding-mode voltage control of a buck converter," IEEE Transactions on Industrial Electronics, vol. 65, no. 1, pp. 844-854, 2018.

[5] Z. Tian, Z. Lyu, J. Yuan, C. Wang, "UDE-based sliding mode control of DC-DC power converters with uncertainties," Control Engineering Practice, vol. 1, no. 83, pp. 116-128, 2019.

[6] Z. Chen, W. Gao, J. Hu, X. Ye, "Closed-loop analysis and cascade control of a nonminimum phase boost converter," IEEE Transactions on power electronics, vol. 26, no. 4, pp. 1237-1252, 2011.

[7] M Ranjani, and P Murugesan., "Optimal fuzzy controller parameters using PSO for speed control of Quasi-Z Source DC/DC converter fed drive," Applied Soft Computing, vol. 1, no. 27, pp. 332-56, 2015.

[8] SR Rex, and DMMSR Praba, "Design of PWM with four transistor comparator for DC-DC boost converters," Microprocessors and Microsystems, vol. 72, 2020.

[9] M Moutchou, and A Jbari, "Fast photovoltaic IncCond-MPPT and backstepping control, using DC-DC boost converter," International Journal of Electrical and Computer Engineering (IJECE), vol. 10, no. 1, pp. 1101-1112, 2020.

[10] RA. Kadhim, "Design and simulation of closed loop proportional integral (PI) controlled boost converter and 3-phase inverter for photovoltaic (PV) applications," Al-Khwarizmi Engineering Journal, vol. 15, no. 1, pp. 10-22, 2019.

[11] T.M. Ali, and B.M.H. Jassim, "Modeling and Simulation of Sensorless Speed Control of a Buck Converter Controlled Dc Motor," Al-Khwarizmi Engineering Journal, vol. 6, no. 1, pp. 80-87, 2010.

[12] Singh, G. and Kundu, S., "An efficient DC-DC boost converter for thermoelectric energy harvesting," $A E U$ International Journal of Electronics and Communications, vol. 118, 2020.

[13] Kumar, S. and Vijayakumar, K., "Simulation and experimental comparative analysis of the DC-DC converter topologies for wind driven SEIG fed DC nanogrid," Electric Power Systems Research, vol. 181, 2020.

[14] M.H. Miry, A.H. Miry, H.K. Khleaf, "Adaptive noise cancellation for speech employing fuzzy and neural network," 1st internation Conference on Energy, power and Control (EPC-IQ), 2010.

[15] A.H. Mary, "Generialized PID controller based on particle swarm optimization," Iraqi Journal of Computers, Communication and Control \& Systems Engineering, vol. 11, no. 1, pp. 114-122, 2011.

[16] A.H. Miry, A.H. Mary, M.H. Miry, "Mixed robust controller with optimized weighted selection for a DC servo motor," Proce. of the Int. Conference on Information and Communication Technology, pp. 178-183, 2019.

[17] A.H. Miry, A.H. Mary, M.H. Miry, "Improving of maximum power point tracking for photovoltaic systems based on swarm optimization techniques," IOP Conference Series: Materials Science and Engineering, vol. 518, no. $4,2019$.

[18] A.H. Mary, T. Kara, A.H. Miry., "Inverse kinematics solution for robotic manipulators based on fuzzy logic and PD control," Al-Sadeq International Conference on Multidisciplinary in IT and Communication Science and Applications (AIC-MITCSA), pp. 1-6, 2016.

[19] T. Kara, A.H. Mary, "Robust trajectory tracking control of robotic manipulators based on model-free PID-SMC approach," Journal of Engineering Research, vol. 6, no. 3, pp. 170-188, 2018.

[20] T. Kara, A.H. Mary, "Feedback-based IKP solution with SMC for robotic manipulators: The SCARA example," International Advanced Researches and Engineering Journal, vol. 2, no. 1, pp. 27-32, 2018.

[21] T. Kara, A.H. Mary., "Adaptive PD-SMC for Nonlinear Robotic Manipulator Tracking Control," Studies in Informatics and Control, vol. 1, no. 26, pp. 49-58, 2017.

[22] A.H. Mary, T. Kara, "Robust proportional control for trajectory tracking of a nonlinear robotic manipulator: LMI optimization approach," Arabian Journal for Science and Engineering, vol. 41, no. 12, pp. 5027-5036, 2016.

[23] S. Oucheriah, L. Guo, "PWM-based adaptive sliding-mode control for boost DC-DC converters," IEEE Transactions on Industrial Electronics, vol. 60, no. 8, pp. 3291-3294, 2013.

[24] W.H. Che, "Disturbance observer based control for nonlinear systems," IEEE/ASME transactions on mechatronics, vol. 9, no. 4, pp. 706-710, 2004.

[25] Y. Pan, C. Yang, L. Pan, H. Yu, "Integral sliding mode control: performance, modification, and improvement," IEEE Transactions on Industrial Informatics, vol. 14, no. 7, pp. 3087-96, 2018. 